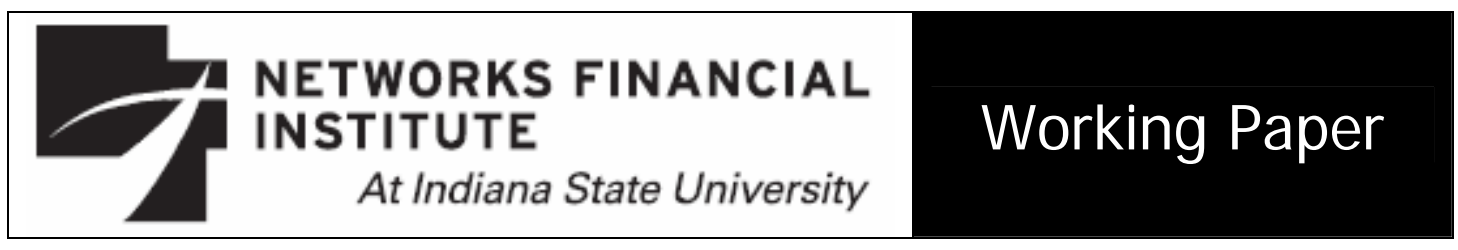

2006-WP-03

July 2006

\title{
Moral Hazard and Repayment Performance Under Group Lending
}

\author{
Joel M. Guttman
}

Abstract: This paper develops a model of the strategic interaction of borrowers in the framework of group lending, in an environment characterized by moral hazard.

Unlike previous papers, monitoring by one group member of his or her peers is not a crucial feature of the model. Even without monitoring, repayment performance under group lending can compare favorably to such performance under individual liability. The effects of allowing monitoring and of changing group size are also investigated.

About the Author: Joel M. Guttman is a Senior Fellow at Networks Financial Institute. Guttman is currently serving as an associate professor in the department of economics in Bar-Ilan University. He has also served as a visiting professor at the University of Chicago, Brown University and the Helsinki School of Economics. His research areas include evolution of trust and cooperation, economic growth and conflict (internal and external), public economics, applied game theory, and defense economics. He has published numerous articles in scholarly journals including American Economic Review, Journal of Political Economy, Journal of Public Economics, and Economic Journal. He received his Ph.D. in economics from the University of Chicago.

Keywords: group lending, group liability, microfinance, microcredit, moral hazard, monitoring

The views expressed are those of the individual author and do not necessarily reflect official positions of Networks Financial Institute. Please address questions regarding content to Joel M. Guttman at guttman@mail.biu.ac.il. Any errors or omissions are the responsibility of the author. 


\title{
Moral Hazard and Repayment Performance Under Group Lending
}

\author{
Joel M. Guttman*
}

\section{Introduction}

Over the last twenty years, microfinance programs have become a widely adopted tool for making productive capital accessible to the poor in developing countries. Such programs, featuring small loans and joint liability of groups of borrowers, account for a significant share of the loans made available to poor producers in such countries. A survey of two hundred of the thousands of microfinance organizations worldwide, in September 1995, found 13 million loans worth $\$ 7$ billion outstanding at that time. In February 1997, the Microcredit Summit sought more than $\$ 20$ billion to supply credit to 100 million poor households over the following ten years. ${ }^{1}$

Microfinance programs are believed to be highly successful as compared to traditional moneylenders and other sources of credit in less-developed countries. The success of microfinance is reflected by unusually high repayment performance, often at the level of 96 to 98 percent. Several theoretical studies have sought to explain the apparent success of microfinance institutions. Most of the explanations that have been offered focus on informational advantages possessed by members of group lending programs, relative to the information that can be accessed by lending institutions, as well as emphasizing the advantage of members of group lending in enforcing obligations to the lending institution. More specifically, two types of informational advantages have been analyzed:

- The first type of informational advantage is related to the problem of adverse selection that occurs in conventional lending arrangements when the lender cannot observe the "type" of the borrower - i.e., whether she is a "safe" borrower who will be willing and able to repay her debt, or a "risky" borrower who has a high probability of defaulting. While the lending institution can ascertain the type of the borrower only at a high cost, members of a group of borrowers in the tightly knit

${ }^{*}$ Department of Economics, Bar-Ilan University, 52900 Ramat-Gan, Israel.

${ }^{1}$ Navajas, et al. (2000), p. 334. The 1995 survey was reported by Paxton (1996), cited by Navajas, et al. (2000). 
social structure of traditional villages have much more complete information of the types of their fellow members. It has been claimed [Ghatak (1999), van Tassell (1999)] that if individuals can choose their fellow members in group lending programs, and if side-payments can be made between members to induce desirable (safe) borrowers to join their groups, then borrowers will tend to sort themselves into relatively homogenous groups of safe and risky borrowers. While I have shown elsewhere (Guttman 2006) that this argument is incorrect under highly plausible assumptions, it remains true that if side-payments are not feasible, self-sorting will tend to occur if groups can form themselves. Such "assortative matching," if it does occur, permits the lending institution to solve the problem of adverse selection by offering a menu of alternative loans, in which the degree of joint liability and some other parameter (such as the interest rate) are both allowed to vary.

- The second informational advantage of groups of borrowers over external lending institutions is related to the problem of ex ante moral hazard. Borrowers have an incentive to take actions - relating to project choice or to the level of effort they invest in making their projects succeed - which increase the likelihood that they will default. If the legal system could be relied upon to enforce the borrower's contractual obligations to the lender, or if the borrower had substantial collateral which could be repossessed by the lender in the event of default, this problem of moral hazard would be absent. But the extreme poverty of the borrowers who are the target population of microfinance programs virtually precludes their possession of such collateral, and legal enforcement in such societies is costly and imperfect, making default (induced by the choice of risky projects, or by low levels of effort invested in the projects undertaken with borrowed funds) relatively probable. Microfinance theorists have argued that members of borrowing groups can monitor their peers at relatively low cost in order to determine if default was caused by low levels of effort or by imprudent project choice, and can apply sanctions to delinquent borrowers in such cases. Such sanctions may well be unavailable to outside lending institutions, and monitoring may not be a viable option for such institutions.

Aside from these informational advantages, theorists [Besley and Coate (1995), Armendáriz de Aghion (1999)] have argued that group lending can solve the problem of strategic default or ex post moral hazard. Strategic default occurs when a borrower defaults simply to save the cost of repaying, 
rather than due to failure of his or her project. The lack of efficient and cheap legal enforcement and of collateral makes strategic default a potentially serious problem in the case of poor borrowers in developing countries. Internal group sanctions, applied to strategic defaulters, may be an efficient solution to this problem.

The present paper is a contribution to the literature on group lending when ex ante moral hazard is part of the economic environment. Due to the complexity of this problem, the existing literature has imposed very strong simplifying assumptions, which limit the applicability of the results that have been obtained. The first such paper, Stiglitz (1990), made the strong simplifying assumption that group members can sign a binding agreement regarding their choice of project (where each member has an incentive to choose a riskier project than is optimal for the group). Such an assumption essentially assumes away the problem of monitoring and enforcing agreements among group members. Banerjee, Besley and Guinnane (1994) avoid the assumption made by Stiglitz (1990), but impose instead an assumption that in the two-member group they study, only one member takes a loan, and the other member's role is limited to monitoring the borrower. This assumption enormously simplifies the game under consideration, by making it a sequential-move or Stackelberg game, but has the cost of a great decrease in realism. Later work [Madajewicz (2003), Conning (2005)] models a more realistic, simultaneous-move game, but allows members to have collateral which can be easily repossessed by the lending institution - a crucial feature absent from real-world microfinance programs in many instances.

The present paper avoids the restrictive assumptions made by earlier work, at the cost of additional complexity of the model. The main results in this model cannot be established using analytical proofs, but only illustrated using numerical simulations. The value in such an approach is primarily in discovering theoretical possibilities that have been ignored by earlier models.

Section 2 of the paper sets out the assumptions of the model and analyzes the model in the benchmark case, in which group members cannot monitor each other's effort levels and the size of the group is limited to two members. Section 3 extends the model to the case of three members and allows the players to monitor each other's effort levels. Section 4 offers concluding observations. 


\section{Basic Model}

\subsection{Assumptions}

Consider a group consisting of two, risk-neutral members. Each member $i \in(1,2)$ is offered by the lending institution to take a loan whose size is $L_{i}$, enabling him or her to undertake an investment project. The return of the project is a dichotomous, random variable. If the project "succeeds," it yields the income $y_{i}$. If the project "fails," it provides a zero return. ${ }^{2}$

The investment project requires productive effort of the borrower in order to succeed. Thus the project's probability of success $p_{i}$ is a function of member $i$ 's effort level $e_{i} \in[0,1]$. For simplicity, it is assumed that $p_{i}$ is independent of the success or failure of the other member's project. We thus assume

$$
p_{i}=\alpha e_{i}
$$

where $\alpha \in(0,1)$ is a parameter measuring the degree to which the success of the project depends on the member's effort.

The income produced by a successful project, $y_{i}$, is a function of the amount of capital invested, which in turn is equal to the loan size, $L_{i}$. I will assume a simple functional form:

$$
y_{i}=\rho L_{i}^{\phi},
$$

where $\rho>0$ and $\phi \in(0,1)$ are exogenous parameters. ${ }^{3}$

While I assume that the success or failure of each member's project is observed by the other group member and by the lending institution, the member's effort level is unobservable and cannot be inferred from the success or failure of his or her project. Given that $\alpha<1$, failure of the project does not logically imply that the member exerted less than the maximum level of effort (unity). For example, if $\alpha=0.5$, the project will succeed with a

\footnotetext{
${ }^{2}$ This assumption is made only for simplicity of exposition. Generalizing the model, to allow for some return to be obtained in the case of failure, would not change the results fundamentally.

${ }^{3}$ Combining this specification of $y_{i}$ with (1), we obtain, for the member's expected income,

$$
p y_{i}=\alpha e_{i} \rho L_{i}^{\phi}
$$
}

If we regard this expression as a production function, and $e_{i}$ and $L_{i}$ as the inputs, we find that this function exhibits increasing returns to scale. I nevertheless use this specification to simplify the analysis. Raising $e_{i}$ to the power $1-\phi$, thus making the function linearly homogenous, would not change the basic results. 
probability of only 50 percent even if the member exerts a 100 percent level of effort.

The group undertakes to repay the loan $L_{1}+L_{2}$ to the lending institution, with interest. Denote the (exogenous) interest rate, inclusive of the principal, as $r$. Thus the group undertakes to repay $r\left(L_{1}+L_{2}\right)$. The two members agree that each will repay his loan if his project succeeds.

If the member's project fails, she has no resources (no collateral) with which to repay her loan. But each member agrees that if her own project succeeds while her fellow member's project fails, then she will repay both her own loan and a proportion $\gamma \in(0,1]$ of her fellow member's loan. The degree of joint liability, $\gamma$, is determined by the lending institution. I assume that each member is able to fulfill both his own loan repayment obligation and this joint liability obligation when his project succeeds and his peer's project fails, implying that

$$
y_{i} \geq r\left(L_{i}+\gamma L_{j}\right)
$$

where $i \neq j$. This weak inequality will be called the repayment feasibility constraint.

The group views this joint liability feature as a form of mutual insurance. Thus a member whose project failed does not have to repay his fellow group member who (partially) repaid his debt, at a later date when his (subsequent) project succeeds. ${ }^{4}$

Under joint liability, each member has an incentive to exert less than the level of effort that he would exert without joint liability. One reason for this moral hazard problem is simply that, with joint liability, a member who exerts a low level of effort shifts part or all of the liability for failure of his project, to his fellow group member. Additionally, in the event that his project succeeds while his fellow member's project fails, he will have to repay the proportion $\gamma$ of his fellow member's debt to the lending institution. By exerting a low level of effort, reducing his own probability of success, he avoids this eventuality.

Under the terms of the agreement, the group will default if both members' projects fail, and the lending institution has no recourse, in this event, of regaining the loans it made. Nevertheless, I assume that the institution declares that it will withhold future loans from the group if the group ever

\footnotetext{
${ }^{4}$ This assumption is made in order to allow joint liabililty to generate a moral hazard problem, as explained in the next paragraph. Aside from the "mutual insurance" motivation for this assumption, one can note that the group only has a limited "moral claim" on a member whose project failed, since it is impossible to prove that this failure was a consequence of a lack of effort exerted by the member.
} 
defaults. ${ }^{5}$ The net present value of such future loans to member $i$ is denoted as $V_{i}{ }^{6}$ If the group "partially" defaults, i.e., if member $i$ 's project succeeds and member $j$ 's project fails, in which case the group only partially repays its debts when $\gamma<1$, the lending institution does not withhold future loans, provided that the group makes the agreed-upon repayment, $r\left(L_{i}+\gamma L_{j}\right)$.

Effort is costly. The cost of effort $c_{i}$, for simplicity, is assumed to be quadratic in effort:

$$
c_{i}=\beta e_{i}^{2},
$$

where $\beta>0$.

The two members play a game with two stages. (Since the borrowers and the lending institution are viewed as playing an infinitely repeated game, these two stages are infinitely repeated. The second stage of each repetition may occur at the same time as the first stage of the following repetition, or at some later date.) In the first stage, the members take loans and exert effort in production. In the second stage, the outcomes (success or failure of each project) are realized, and the members pay back their loans, with interest, if their projects succeed.

Since the model focuses on ex ante moral hazard rather than strategic default, an assumption is made that ensures that repaying of loans is a Nash equilibrium in the final stage, in the sense that each player would wish to repay in order to preserve access to future loans. ${ }^{7}$ Suppose that the present value of such future loans, $V_{i}$, is greater than the loan payment required of the member, $r L_{i}$, for each member $i$. Then if both members' projects succeed, each member will prefer to repay his loan rather than lose $V_{i}$, provided that the other member repays as well. Therefore the condition

$$
V_{i}>r L_{i} \forall i
$$

\footnotetext{
${ }^{5}$ This can be interpreted as a trigger strategy in a repeated game, played between the borrowers and the lending institution.

${ }^{6} \mathrm{~A}$ formal definition of $V_{i}$, in the special case in which the borrowers have no alternative source of funds, will be given in Section 2.2. If there are alternative sources of loans, then $V_{i}$ is the difference between the present value of loans and the corresponding present value of future loans from the next-best source of loans. In other words, $V_{i}$ measures the rent deriving from the borrower's long-term relationship with the lending institution.

An alternative interpretation of $V_{i}$ is the reputational loss suffered by the group if it defaults. Under this interpretation, even when there are alternative sources of loans which are equally profitable to the group members, $V_{i}$ does not disappear.

${ }^{7}$ Even if such an equilibrium exists, however, it is not usually a unique equilibrium. Some form of informal coordination must be implicitly assumed, in general, in order to explain why the "repaying" equilibrium is selected.
} 
will be called the weak self-enforcement condition.

The above condition is called "weak" because a stronger condition can be formulated, which ensures that even when member $j$ 's project fails, member $i$ will be motivated to repay both her own loan and the proportion $\gamma$ of member $j$ 's loan which she is committed to repay by the joint liability requirement. This condition is

$$
V_{i}>r\left(L_{i}+\gamma L_{j}\right) \forall i \neq j .
$$

Note that if this condition holds, the previous "weak" self-enforcement condition automatically holds as well. The latter condition can therefore be called the strong self-enforcement condition. In order to ensure that upholding of the borrowers' agreement with the lending institution is a Nash equilibrium in the final stage (and thus to focus attention on the first stage, in which effort levels are determined), I will assume that the strong selfenforcement condition holds.

The two members choose their effort levels simultaneously, and the effort levels, which determine the probability that the loans will be repaid, are assumed to be consistent with a Nash equilibrium. We focus throughout on interior equilibria, i.e., equilibria in which both members exert a positive level of effort. When the members are identical in terms of the parameters $y_{i}, L_{i}$, and $V_{i}$, I assume that such equilibria will be symmetric equilibria.

\subsection{Analysis of the Model}

Member $i$ 's expected payoff, expressed as a present value at the first time period, is

$$
\pi_{i}=\frac{p_{i} y_{i}}{r}-c_{i}-\left[p_{i} L_{i}+\gamma p_{i}\left(1-p_{j}\right) L_{j}\right]+\left[1-\left(1-p_{i}\right)\left(1-p_{j}\right)\right] V_{i}
$$

where $p_{j}$ is the other member's probability of success and $e_{j}$ is the other member's effort level. The first bracketed term on the r.h.s. is the member's expected repayment to the lending institution. ${ }^{8}$ Within that bracketed term, the first term is member $i$ 's expected repayment of his own loan (which he repays only if his project succeeds), and the second term is his expected repayment of his fellow member's loan, which will occur only if his own

${ }^{8}$ Note that the gross interest term $r$ is absent, since the repayment will take place one period later, implying that, to obtain present value, we must divide this term by the gross interest rate $r$ (1 plus the net interest rate). At the same time, the $L_{i}$ and $L_{j}$ in the first bracketed term must be multiplied by $r$ to obtain the relevant repayment terms. Thus the $r$ terms cancel out. (The final term in (4) is already discounted back to $t=0$; see next footnote.) 
project succeeds and the fellow member's project fails. The second bracketed term is member $i$ 's present value of future loans, $V_{i}$, which will be received only if at least one of the two members' projects succeeds, an event whose probability is $\left[1-\left(1-p_{i}\right)\left(1-p_{j}\right)\right] .^{9}$

Substituting (1) and (3) into (4), we have

$$
\begin{aligned}
\pi_{i}= & \frac{\alpha e_{i} y_{i}}{r}-\beta e_{i}^{2}-\left[\alpha e_{i} L_{i}+\gamma \alpha e_{i}\left(1-\alpha e_{j}\right) L_{j}\right] \\
& +\left[1-\left(1-\alpha e_{i}\right)\left(1-\alpha e_{j}\right)\right] V_{i} .
\end{aligned}
$$

The first-order condition for maximum expected payoff is (at an interior solution $)^{10}$

$$
\frac{\partial \pi_{i}}{\partial e_{i}}=\frac{\alpha y_{i}}{r}-2 \beta e_{i}-\alpha\left(L_{i}+\gamma L_{j}\right)+\alpha^{2} \gamma e_{j} L_{j}+\alpha\left(1-\alpha e_{j}\right) V_{i}=0
$$

yielding

$$
e_{i}^{*}=\left(\frac{\alpha}{2 \beta}\right)\left\{\left[\frac{y_{i}}{r}-\left(L_{i}+\gamma L_{j}\right)+V_{i}\right]-\alpha\left(V_{i}-\gamma L_{j}\right) e_{j}\right\}
$$

for member $i$ 's optimal effort level. Equation (6) is member $i$ 's reaction function in the game. The repayment feasibility constraint (2) implies that the term in the square brackets is positive. This implies that member $i$ 's reaction function has a positive intercept-i.e., when the other member's effort level is zero, member $i$ exerts a positive level of effort.

The slope of the member's reaction function is

$$
\frac{\partial e_{i}^{*}}{\partial e_{j}}=-\frac{\alpha^{2}\left(V_{i}-\gamma L_{j}\right)}{2 \beta}
$$

${ }^{9}$ We can now give a formal definition of $V_{i}$, assuming that the agent has no alternative source of loans. Suppose that the agent receives a loan $L_{i}$ in each time period. Let (discrete) time be indexed by $t$. For simplicity, assume that the agent has an infinite time horizon. Then, at $t=0$, the present value of access to future loans is

$$
V_{i 0}=\sum_{t=1}^{\infty} \frac{\left[1-\left(1-p_{i t}\right)\left(1-p_{j t}\right)\right]^{t}}{r^{t}}\left\{\frac{p_{i t} y_{i t}}{r}-c_{i}-\left[p_{i t} L_{i}+\gamma p_{i t}\left(1-p_{j t}\right) L_{j}\right]\right\} .
$$

The expression preceding the curly brackets is the agent's discount factor. In particular, the numerator in this expression is the probability that stage $t$ will in fact be reached in the long-term relationship of the borrower and the lending institution, since this is the probability that there was never a stage, up to stage $t$, in which both borrowers' projects failed.

${ }^{10}$ The change in $e_{i}\left(\partial e_{i}\right)$ is to be viewed as one-shot change in $e_{i}$, which will return to its original value in the following repetition of the repeated game. Thus each repetition is in Nash equilibrium, a requirement implied by subgame perfection. In this calculation, $V_{i}$, which is calculated at the equilibrium point and is based on future payoffs only, does not change. 
Thus the sign of the slope of the reaction function depends on whether $V_{i}$ is greater or less than $\gamma L_{j}$. If $V_{i}>\gamma L_{j}$, the reaction function has a negative slope. Note that $V_{i}>\gamma L_{j}$ is directly implied by the strong self-enforcement condition, which we have assumed to hold. ${ }^{11}$

Let us make the simplifying assumption that $L_{i}=L_{j}$ and $V_{i}=V_{j}$. (When $L_{i}=L_{j}$, we also have $y_{i}=y_{j}$.) To simplify notation, the subscripts $i$ and $j$ will be suppressed for these variables. The equilibrium in the first stage of the game will then be assumed to be symmetric. The equilibrium effort levels can be computed by setting $e_{i}=e_{j}=e$ in (6) and solving for $e$, thus obtaining

$$
\bar{e}=\frac{\frac{y}{r}+V-L(1+\gamma)}{\alpha(V-\gamma L)+(2 \beta / \alpha)}
$$

for the equilibrium level of effort. Note that the strong self-enforcement condition implies that the denominator of (7) is positive, while the repayment feasibility constraint (2) implies that the numerator of (7) is positive. Thus $\bar{e}$ must be positive.

We can check the effects of the parameters of the loan contract, particularly $\gamma$ and $L$, on the equilibrium level of effort, by differentiating $\bar{e}$ with respect to these parameters. ${ }^{12}$ To derive the effect of $\gamma$ on $\bar{e}$, it is helpful first to take the logarithm of $\bar{e}$ in (7) and then differentiate with respect to $\gamma$ :

$$
\frac{\partial \ln \bar{e}}{\partial \gamma}=-\frac{L}{\frac{y}{r}+V-L(1+\gamma)}+\frac{\alpha L}{\alpha(V-\gamma L)+(2 \beta / \alpha)} .
$$

Given that $\bar{e} \leq 1$, the denominator of the first expression on the r.h.s. of (8), which is the numerator in (7), is no greater than the denominator of the second expression in (8), which is the denominator in (7). Since $\alpha<1$,

${ }^{11}$ Note that the absolute value of $\partial e_{i}^{*} / \partial e_{j}$ will be less than unity if

$$
V_{i}-\gamma L_{j}<\frac{2 \beta}{\alpha^{2}}
$$

When the slopes of the members' reaction functions are both between -1 and zero, the equilibrium in the first stage of the game will be stable, in the sense that if the effort levels are not initially at their equilibrium levels, a process of reaction and counter-reaction of the two effort levels (when each member takes his peer's effort level as given) will lead to the equilibrium. This condition also implies that the interior equilibrium, in which both effort levels are positive, is the unique equilibrium of the game.

${ }^{12}$ The effect of the (gross) interest rate $r$ on the equilibrium level of effort is trivially negative, as can be seen by inspection of (7). 
it follows that $\partial \ln \bar{e} / \partial \gamma$ is negative, implying that increasing $\gamma$ will decrease the equilibrium level of effort. The intuitive explanation for this result is that increasing $\gamma$ exacerbates the moral hazard problem. When $\gamma$ increases, if a member's own project fails, he can shift a greater amount of liability to the other group member. Similarly, with a larger $\gamma$, each member bears a greater expected cost of having to pay back his fellow member's debt. Both effects work to make shirking a more attractive option.

To examine the effect of the loan size $L$ on the equilibrium level of effort, we must differentiate (7) with respect to $L$, after first substituting $\rho L^{\phi}$ for $y$. The resulting derivative is ambiguous in sign. On the one hand, increasing $L$ increases $y$, the income received from a successful project. This effect increases the incentive to exert effort. On the other hand, increasing $L$ increases the member's expected loan repayment, which she must pay only when her project succeeds. This effect makes exerting effort less worthwhile, since the higher the effort level, the greater the probability that the loan will have to be repaid.

Until now, we have examined the effects of $\gamma$ and $L$ on the equilibrium level of effort. From the viewpoint of the lending institution, however, the optimal choice of $\gamma$ involves additional considerations. In particular, by increasing $\gamma$, the lending institution reduces its expected loss of partial repayment when one member's project succeeds and the other member's project fails. To take the extreme case, under full joint liability $(\gamma=1)$, the lending institution receives a full repayment unless both members' projects fail. Thus the optimal choice of $\gamma$ is not a trivial matter, since increasing $\gamma$ normally decreases the equilibrium level of effort.

To analyze the optimal $\gamma$ and $L$ from the viewpoint of the lending institution, consider the lender's expected revenue from repayment, per dollar lent out:

$$
\begin{aligned}
\Pi & =\left[\frac{2 L(\alpha \bar{e})^{2}+2(1+\gamma) L \alpha \bar{e}(1-\alpha \bar{e})}{2 L}\right] r \\
& =\left[(1+\gamma) \alpha \bar{e}-\gamma(\alpha \bar{e})^{2}\right] r .
\end{aligned}
$$

The first term in the square brackets, in the numerator in the first line of (9), is the expected revenue from repayment when both members' projects succeed. The probability of this event occuring is $(\alpha \bar{e})^{2}$, and the revenue (from the loans to the two members) is $2 L r$. The second term is the revenue when one member's project succeeds and the other member's project fails. There are two possible such events, each with the probability $\alpha \bar{e}(1-\alpha \bar{e})$. In each such event, the revenue to the lending institution is $(1+\gamma) L r$. 
Differentiating (9) with respect to $\gamma$ and $L$, after substituting the r.h.s. of (7) for $\bar{e}$, produces huge mathematical expressions that cannot yield analytical results. We are therefore forced to perform numerical simulations. Figures 1 through 3 show the results of a typical simulation, based on the following parameter values: $\rho=3, \phi=0.5, r=1.05, \alpha=0.9, \beta=1.3$, and $V=2.5$. These parameter values are chosen so that (a) the repayment feasibility constraint (2) is satisfied at the equilibrium, (b) the member's profit in the second stage of each repetition of the game [the first line in (5)] is non-negative at the equilibrium, ${ }^{13}$ (c) the weak and strong self-enforcement conditions are satisfied, and (d) $\bar{e}$ must be no greater than unity. Figure 1 shows the expected revenue of the lending institution, $\Pi$, as a function of $\gamma$ and $L$, when viewed from the side of the $\gamma$ variable. As the figure shows, $\Pi$ is maximized by setting $\gamma=1$, i.e., full joint liability. Figure 2 shows the same figure when viewed from the side of the $L$ variable. The figure shows that $\Pi$ is maximized by setting $L$ approximately equal to 0.87 . Given these values for $\gamma$ and $L$, $\Pi$ reaches a value of 0.96 , meaning that about 96 percent of each dollar lent out is paid back (including interest).

Figure 3 shows the equilibrium level of effort expended by the two group members, under the same parameter assumptions. The figure highlights the fact that the equilibrium effort level decreases monotonically as $\gamma$ increases. Despite this fact, as we saw in Figure 1, it is optimal for the lending institution to set $\gamma=1$, since this value of $\gamma$ implies that the loan is fully repaid unless both members' projects fail. At $\gamma=1$ and $L=0.87, \bar{e}$ is about 0.8 , i.e., each member exerts about 80 percent of his or her maximum effort level.

\section{Extensions of the Model}

This section presents the results of two extensions of the model: (a) enlarging the group size to three members, and (b) allowing members to monitor each other's effort levels.

\subsection{Increasing Group Size}

Very little is known in the literature on the effect of group size on repayment performance. In a rare attempt to analyze this question, Armendáriz de Aghion (1999) obtained ambiguous results. In the present model, as well, it is impossible to obtain a clearcut, analytical answer to this question.

\footnotetext{
${ }^{13}$ The assumption here is that the member has the option not to take the loan and to receive a zero payoff. Thus the member must receive a non-negative payoff in each repetition of the game to ensure that he or she will take the loan.
} 
Moral Hazard and Repayment Performance Under Group Lending 12

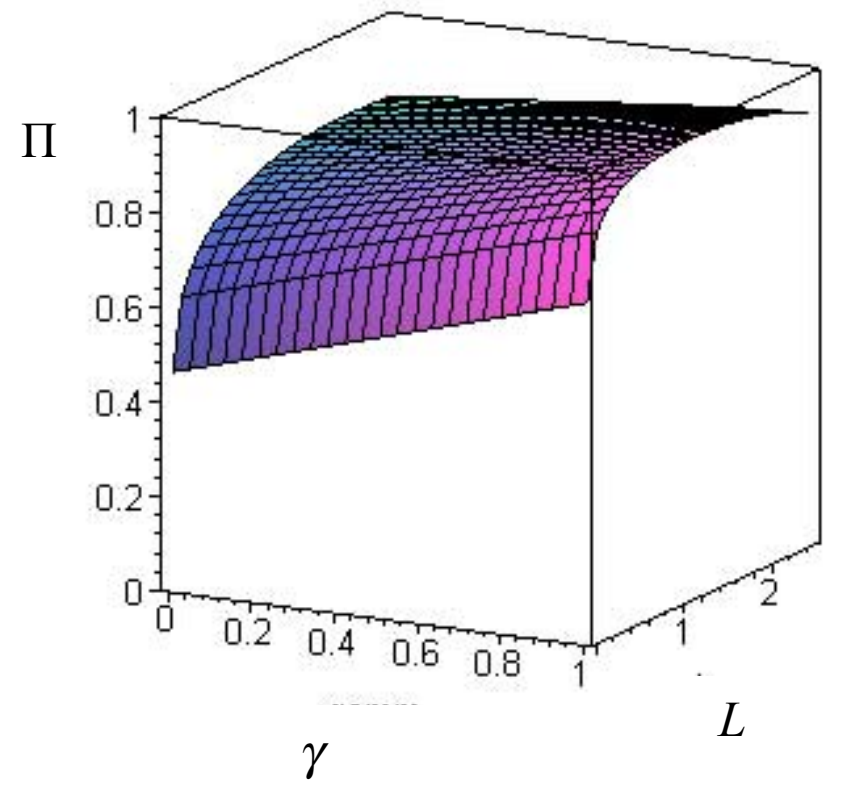

Figure 1: Repayment rate as function of $\gamma$ and $L$ (viewed from $\gamma$ axis) 
Moral Hazard and Repayment Performance Under Group Lending 13

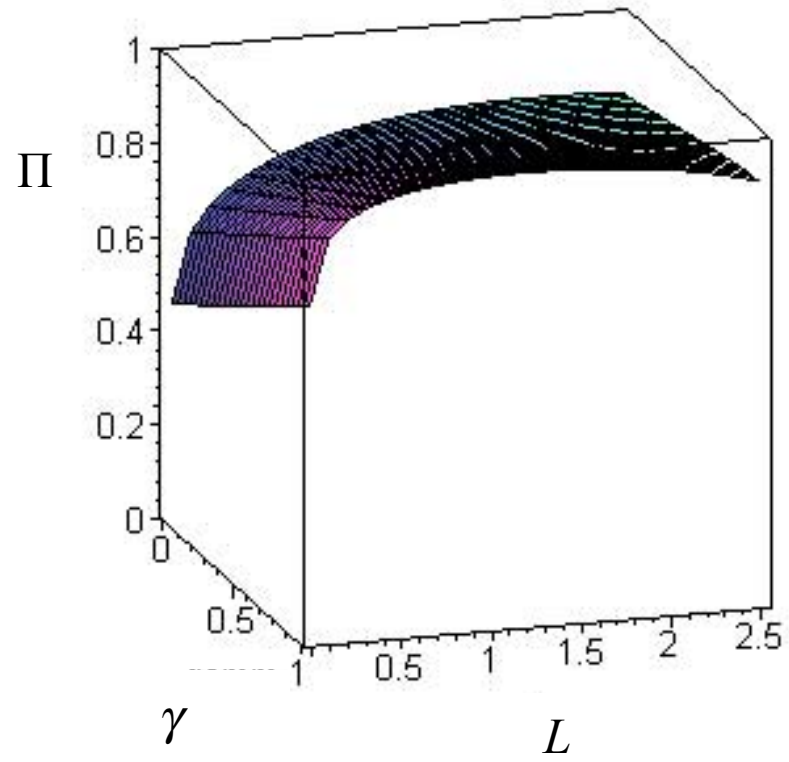

Figure 2: Repayment rate as function of $L$ and $\gamma$ (viewed from $L$ axis) 
Moral Hazard and Repayment Performance Under Group Lending 14

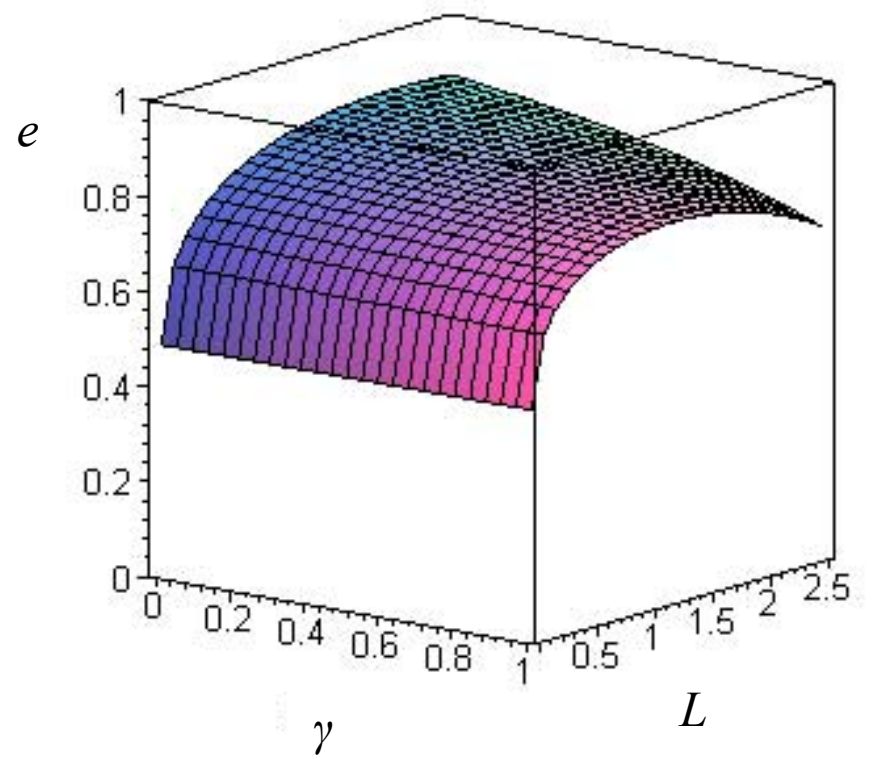

Figure 3: Equilibrium effort level as function of $\gamma$ and $L$ 
Suppose there are three members of the group, indexed $i, j$, and $k$. Member $i$ 's objective function, analogous to (5) for the two-member case, is

$$
\begin{aligned}
\pi_{i}= & \frac{\alpha e_{i} y_{i}}{r}-\beta e_{i}^{2}-\alpha e_{i} L_{i} \\
& -\gamma \alpha e_{i} \frac{\alpha e_{j}\left(1-\alpha e_{k}\right) L_{k}+\alpha e_{k}\left(1-\alpha e_{j}\right) L_{j}}{2} \\
& -\gamma \alpha e_{i}\left(1-\alpha e_{j}\right)\left(1-\alpha e_{k}\right)\left(L_{j}+L_{k}\right) \\
& +\left[1-\left(1-\alpha e_{i}\right)\left(1-\alpha e_{j}\right)\left(1-\alpha e_{k}\right)\right] V_{i} .
\end{aligned}
$$

The second and third lines of this equation represent member $i$ 's expected repayment costs when his own project succeeds, but one or both of his fellow members defaults. It is assumed that if only one of the peers defaults, then the share $\gamma$ of the defaulter's loan that must be repaid is divided equally between the two other members. The fourth line of the equation represents member $i$ 's expected benefits from future loans, when the project of at least one of the group members succeeds.

To analyze this case, I again impose symmetry: $L_{i}=L_{j}=L_{k}=L$, and $V_{i}=V_{j}=V_{k}=V$. Equation (10) is then differentiated with respect to $e_{i}$, the derivative is set equal to zero, and the resulting first-order condition is solved for the optimal $e_{i}$ given $e_{j}$ and $e_{k}$. Having obtained borrower $i$ 's reaction function (which, unlike (6) in the two-member case, is not linear in $e_{j}$ and $e_{k}$ ), a symmetric equilibrium is imposed: $e_{i}=e_{j}=e_{k}=\bar{e}$. The resulting equation, when there are three members in the group, is quadratic in $\bar{e}$, yielding two roots. Only one root, however, lies in the relevant range. The expression for this root is again very messy, and will be omitted here.

The main result of this extension of the model (reached by numerical methods, not analytically) is that when group size increases from two to three, individual equilibrium effort levels decline, but the lending institution's expected revenue from repayment $\Pi$ does not necessarily decrease. To understand why $\Pi$ does not necessarily decrease, recall that when $\gamma=1$, for example, the lending institution receives full repayment unless all group members default. If effort levels remain constant when group size increases, the probability that all group members default will decrease. Thus, even if effort levels decrease somewhat with an increase in group size, the probability of the event in which projects of all members fail may decline, and in this case, $\Pi$ would actually increase.

For example, under the parameter assumptions used in Section 2.2, as we saw above, when there are two members in the group, each exerts an effort level of approximately 80 percent, and $\Pi$ is 0.96 . When group size increases to three, the equilibrium effort level of each member decreases to 
60 percent, but $\Pi$ stays approximately constant at 0.95 . If we increase $\beta$ to 2 and keep the other parameters constant, $\Pi$ actually increases slightly when moving from a group with two members to a group with three members.

It should be noted that with the increase in group size, the lending institution keeps $\gamma$ at unity (full joint liability), but optimally decreases the loan $L$ to each member from 0.87 to about 0.80 . The decrease in the optimal loan size derives from the effect of the additional group member in increasing the expected loan payment that each member must make to repay his peers' debts, when they default. (This is also the reason why equilibrium effort levels decrease as the group size increases.) The increased expected loan repayment magnifies the negative marginal effect of $L$ on the members' equilibrium effort levels, thus making a smaller loan optimal.

\subsection{Monitoring of Effort Levels}

Previous studies have argued that group lending programs succeed because of the informational advantage that group members have over the lending institution, allowing them to solve, at least partially, problems of moral hazard, adverse selection, and strategic default. The model developed in Section 2.2 and Section 3.1 does not incorporate such informational advantages, yet (in the example we studied) the repayment rate of the group is about the same as it would be if each member took a loan separately and there was no joint liability. We found that whether there are two or three members in the group, the group repayment rate $\Pi$ is 95 to 96 percent (including interest). This results from an effort level of 80 percent in the case of two members and 60 percent in the case of three members. If two members, for example, were each to take a loan individually with the loan size equal to the loan offered to the group in Section 2.2, each borrower would exert 100 percent effort. ${ }^{14}$ But $\Pi$ would remain approximately constant at about 95

${ }^{14}$ Under individual liability, each borrower's objective function becomes

$$
\pi_{i}=\frac{\alpha e_{i} y}{r}-\beta e_{i}^{2}-\alpha e_{i} L+\alpha e_{i} V
$$

Differentiating w.r.t. $e_{i}$ and equating to zero, we obtain, for the optimal effort level,

$$
e_{i}^{*}=\frac{\alpha\left(\frac{y}{r}+V_{i}-L_{i}\right)}{2 \beta} .
$$

Under the parameter values assumed here, $e_{i}^{*}$ as calculated by the above equation is greater than unity. In this case, the borrower would be at a corner solution at which his or her effort level would be 1 . 
percent. ${ }^{15}$

While the above example illustrates the point, seemingly unnoticed by the previous literature, that group lending can perform well relative to individual lending even without informational advantages, ${ }^{16}$ it still is worthwhile to investigate what would happen if such advantages were incorporated into the model. This subsection takes a step in the direction of modeling an informational advantage of group lending programs, in the framework of the model developed in Section 2. Group members are now allowed to monitor and sanction their peers, at a cost to themselves. These sanctions are applied when the peer exerts low effort and this is detected by his fellow member, and the sanction increases linearly as the peer's effort decreases.

In the game that incorporates endogenous monitoring of effort levels, there are three stages. In the first stage, monitoring levels $M_{i}$ and $M_{j}$ are simultaneously chosen. These monitoring levels equal the probability that the monitored member will be detected shirking (choosing a low effort level) in the event that he or she actually shirks. In the second stage, loans are taken and effort levels $e_{i}$ and $e_{j}$ are chosen. In the final stage, the projects either succeed or fail, and the borrowers repay the lending institution according to the agreement specified in Section 2.1.

The cost of monitoring to the monitor $i$ is assumed to be $\delta M_{i}^{2}$, where $\delta$ is a positive parameter.

Member $i$ 's expected payoff function becomes

$$
\begin{aligned}
\pi_{i}= & \frac{p_{i} y_{i}}{r}-c_{i}-\kappa\left(1-e_{i}\right) M_{j}-\delta M_{i}^{2}-\left[p_{i} L_{i}+\gamma p_{i}\left(1-p_{j}\right) L_{j}\right] \\
& +\left[1-\left(1-p_{i}\right)\left(1-p_{j}\right)\right] V_{i},
\end{aligned}
$$

where $\kappa$ is a positive, exogenous parameter, measuring the "marginal cost" of shirking. This function is the same as (4) in Section 2.2, with the addition of two terms: (a) the $\kappa\left(1-e_{i}\right) M_{j}$ term, which is the sanction applied by

${ }^{15}$ When each of two members takes an individual loan, we have

$$
\Pi=\frac{\left[(\alpha e)^{2} 2 L+2 \alpha e(1-\alpha e) L\right] r}{2 L} .
$$

The first term in the numerator is the lending institution's expected revenue from repayment when both borrowers' projects succeed (yielding a revenue of $2 L$ ), which has a probability of $p^{2}=(\alpha e)^{2}$. The second term is the expected revenue from repayment when one borrower's project succeeds and the other project fails (yielding a revenue of $L$ ), an event whose probability is $2 p(1-p)=2 \alpha e(1-\alpha e)$. The above expression for $\Pi$ reduces to $\alpha e r$, which in our numerical example is 0.945 , since $e$ will be unity, $\alpha=0.9$, and $r=1.05$.

${ }^{16} \mathrm{~A}$ notable exception is Conning (2005). Unlike the model of the present paper, however, monitoring is a crucial feature of the Conning (2005) model. 
member $j$ to member $i$ to the extent that member $i$ exerts low effort, and (b) $\delta M_{i}^{2}$, the cost to member $i$ of applying a sanction to member $j$. Substituting (1) and (3) into (11), we obtain

$$
\begin{aligned}
\pi_{i}= & \frac{\alpha e_{i} y_{i}}{r}-\beta e_{i}^{2}-\kappa\left(1-e_{i}\right) M_{j}-\delta M_{i}^{2}-\left[\alpha e_{i} L_{i}+\gamma \alpha e_{i}\left(1-\alpha e_{j}\right) L_{j}\right] \\
& +\left[1-\left(1-\alpha e_{i}\right)\left(1-\alpha e_{j}\right)\right] V_{i} .
\end{aligned}
$$

To solve the game, we first solve the second stage, to determine the equilibrium effort levels. ${ }^{17}$ Differentiating (12) and equating to zero,

$$
\frac{\partial \pi_{i}}{\partial e_{i}}=\frac{\alpha y_{i}}{r}+\kappa M_{j}-2 \beta e_{i}-\alpha\left(L_{i}+\gamma L_{j}\right)+\alpha^{2} \gamma e_{j} L_{j}+\alpha\left(1-\alpha e_{j}\right) V_{i}=0 .
$$

We thus obtain, for the optimal $e_{i}$,

$$
e_{i}^{*}=\left(\frac{\alpha}{2 \beta}\right)\left\{\left[\frac{y_{i}}{r}+\frac{\kappa M_{j}}{\alpha}-\left(L_{i}+\gamma L_{j}\right)+V_{i}\right]-\alpha\left(V_{i}-\gamma L_{j}\right) e_{j}\right\} .
$$

The positive effect on $e_{i}^{*}$ of $M_{j}$, member $j$ 's monitoring level (or, equivalently, the probability that member $i$ 's effort level will be detected by member $j$ ), is clear by inspection of the term in square brackets. The equilibrium in the second stage of the game is obtained by writing the equation corresponding to (13) for member $j$ and solving the two reaction functions simultaneously. As in Section 2, we substitute $\rho L_{i}^{\phi}$ for $y_{i}$, and symmetry of the parameter values is imposed: $L_{i}=L_{j}$ and $V_{i}=V_{j}$. The equilibrium now cannot be assumed to be symmetric, however, since any deviation from the equilibrium in the first stage of the game implies that $M_{i} \neq M_{j}$. The resulting expressions for the equilibrium effort levels are very long and are omitted here. Substituting these expressions into (12) and differentiating with respect to $M_{i}$, we can obtain the optimal monitoring levels, $M_{i}^{*}$ and $M_{j}^{*}$, in the first stage of the game. In these expressions or reaction functions, $M_{i}^{*}$ is a function of $M_{j}^{*}$, and vice-versa. Due to the complexity of the relevant mathematical expressions, we must again resort to numerical simulations. These simulations used the same parameter values assumed in Sections 2.2 and 3.1. Two new parameters, relevant only in the case in which monitoring is allowed, were chosen as follows: $\delta=0.5$ and $\kappa=1$. As in Section 2.2, these parameters were chosen to satisfy the repayment feasibility constraint

\footnotetext{
${ }^{17}$ Repayment of the loan in the final stage, as in the basic model, is not explicitly modeled. I continue to assume that the strong self-enforcement condition holds, so that there exists a Nash equilibrium in the final stage in which the borrowers uphold their agreement with the lending institution. It is further assumed that this equilibrium is selected.
} 


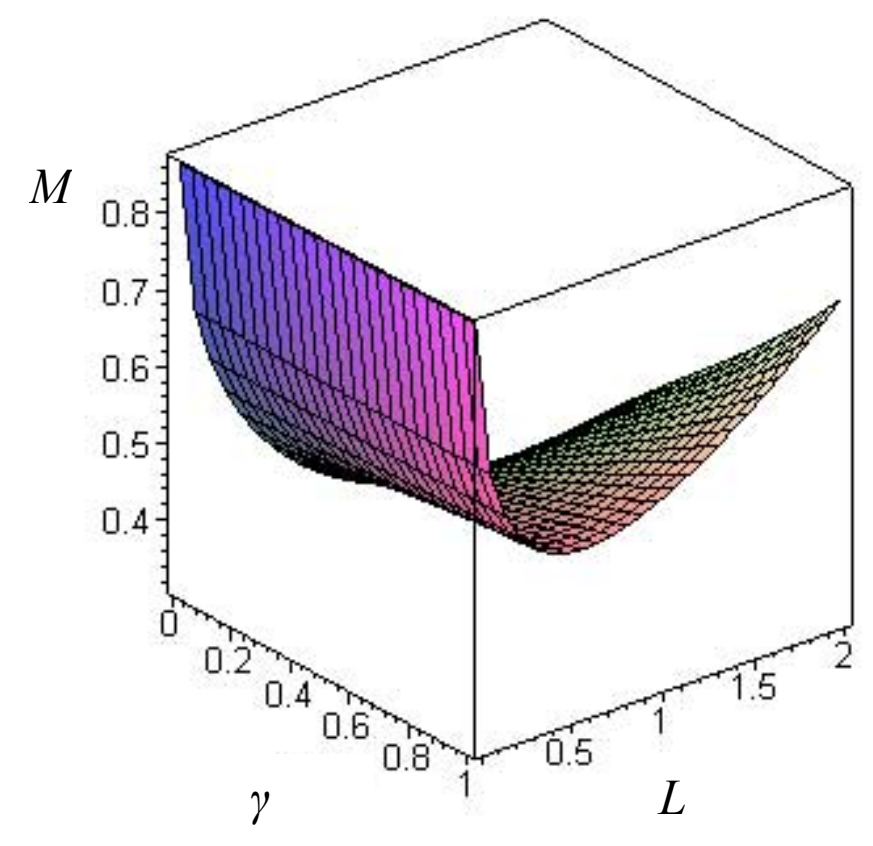

Figure 4: Monitoring level as function of $\gamma$ and $L$

(2) and the strong self-enforcement condition, as well as to ensure that each member's profit in the final stage of each repetition of the game [the first line of (12)] is non-negative.

Figure 4 shows the equilibrium monitoring level as a function of the two parameters of primary interest to the lending institution, $\gamma$ (the degree of joint liability) and $L$ (the size of the loan), under the same assumptions for the other parameters that were made in Section 2.2. The figure shows that the equilibrium monitoring level increases sharply as both $\gamma$ increases and (for sufficiently large $\gamma$ and $L$ ) as $L$ increases. The intuitive explanation of this result is straightforward: as $\gamma$ and $L$ increase, each member's stake in the other member's effort level increases. (A large loan size, for a given level of joint liability, implies that each member will have to pay a relatively large sum to the lending institution if his or her fellow member defaults.) This increases the incentive to monitor.

The implication of the result shown in Figure 4, for the lending institu- 


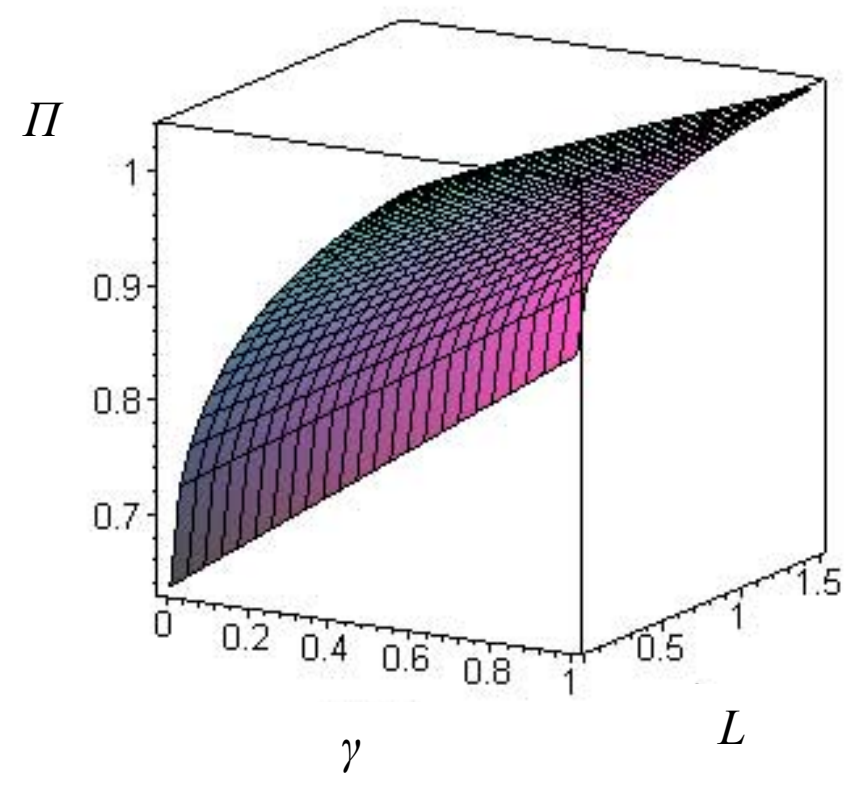

Figure 5: Repayment rate as function of $\gamma$ and $L$

tion, is that it is again optimal to choose the maximum level of joint liability, i.e., full joint liability $(\gamma=1)$. Figure 5 shows $\Pi$, the expected revenue from loan repayment, as a function of $\gamma$ and $L$, under the same parameter assumptions. The figure shows that $\Pi$ is again maximized by setting $\gamma=1$, as in the analysis of Section 2.2, but here $\Pi$ increases monotonically as $L$ increases. The optimal loan size is therefore limited only by the strong selfenforcement condition, which means that in this case of two members, the optimal loan is one-half of $V$, or 1.25 .

Given $\gamma=1$ and $L=1.25$, we find that, in equilibrium, each member now exerts an effort level $e$ of about 96 percent, significantly higher than the effort level of about 80 percent that he or she would exert without monitoring. The expected revenue to the lending institution, per dollar lent out, is 1.023, including interest, or about 0.97 excluding interest. The monitoring level chosen in equilibrium is approximately 0.58 , meaning that a member who shirks has a probability of 0.58 to be detected as shirking. 
Since, in equilibrium, neither member exerts a 100 percent effort level, both are detected as shirking with a probability of 0.58 , but each member suffers a sanction (if detected) whose cost is only $1-e=0.043$.

\section{Concluding Remarks}

This paper has developed a model of group lending in an environment characterized by moral hazard. Unlike previous papers studying this problem, monitoring of one group member by his fellow member is not a crucial component of the model. Monitoring is not necessary to enable the success of group lending. On the contrary, even without such monitoring, we found that the expected repayment revenue received by the lending institution under joint liability can compare favorably with the expected repayment revenue that would be received under individual liability, even though individual effort levels by borrowers are lower under joint liability. This result is due to the fact that under (full) joint liability, the loans received by the group are repaid even when the project of one of the borrowers fails. Indeed, the optimal degree of joint liability from the viewpoint of the lending institution, given that the lending framework is group rather than individual lending, was found to be 100 percent joint liability under plausible parameter values, despite the negative effect of the degree of joint liability on individual equilibrium effort levels.

\section{References}

Armendáriz de Aghion, B., 1999. On the design of a credit agreement with peer monitoring. Journal of Development Economics 60, 79-104.

Banerjee, A.V., Besley, T., and Guinnane, T.W., 1994. Thy neighbor's keeper: The design of a credit cooperative with theory and a test. Quarterly Journal of Economics 109, 491-515.

Besley, T., and Coate, S., 1995. Group lending, repayment incentives, and social collateral. Journal of Development Economics 46, 1-18.

Conning, J., 2005. Monitoring by delegates or by peers? Joint liability loans under moral hazard. Unpublished working paper, City University of New York.

Ghatak, M., 1999. Group lending, local information, and peer selection. Journal of Development Economics 60, 27-50. 
Guttman, J.M., 2006. Repayment performance in group lending programs: A survey. Unpublished working paper, Networks Financial Institute, Indiana State University.

Madajewicz, M., 2003. Capital for the poor: The effect of wealth on the optimal credit contract. Unpublished working paper, Columbia University.

Navajas, S., Schreiner, M., Meyer, R.L., Gonzalez-Vega, C., and Rodriguez-Meza, J., 2000. Microcredit and the poorest of the poor: Theory and evidence from Bolivia. World Development 28, 333-46.

Paxton, J., 1996. A worldwide inventory of microfinance institutions. Washington, DC: World Bank.

Stiglitz, J., 1990. Peer monitoring and credit markets. World Bank Economic Review 4, 351-66.

van Tassell, E., 1999. Group lending under asymmetric information. Journal of Development Economics 60, 3-25. 